\title{
The ASCO Cancer Foundation
}

\section{Kathleen Wiedemer, MBA, CFRE}

It is a privilege to be invited to contribute to the Partners in Cancer Care column in this issue of Journal of Oncology Practice. Participating in this edition of JOP gives us an opportunity to express our gratitude for the work the American Society of Clinical Oncology (ASCO) members do and for member support of the mission of the ASCO Cancer Foundation (TACF), to reflect on our partnership, and to share some of our accomplishments and plans to improve the lives of people with cancer.

First, I would to acknowledge the leadership of the ASCO Clinical Practice Committee (CPC) in supporting the ASCO Cancer Foundation Grants Program by funding a Young Investigator Award (YIA). In 2007, the CPC made ASCO history by funding the first-ever committee-supported YIA. They repeated their generosity and funded another YIA awarded in June. Dr Richard T. Lee from the University of Chicago became the recipient of the 2008 CPC YIA for his abstract titled "Cancer Patients Use of and Communication Patterns about Complementary and Alternative Medicines During Clinical Trials.”

The grants program celebrated its 25 th anniversary at the 2008 ASCO Annual Meeting recognizing more than $\$ 48$ million that has been awarded in grant funding since 1984 . This year, more than $\$ 7.6$ million was awarded to support clinical and translational research designed to improve cancer prevention, treatment, and care. Several new grants were awarded this year including three Clinical Oncology Research Awards (CORA), three Advanced Clinical Research Awards (ACRA), and two Translational Research Professorships.

Dr Nancy Davidson, Immediate Past President of ASCO, announced TACF's establishment of a mission endowment at the 2008 Annual Meeting. This fund will enhance our ability to continue ASCO's important work. The endowment will ensure that the extraordinary promise of the ever-increasing lifesaving advances of new research be made available to oncologists, and ultimately to patients around the world. Our mission endowment was established to provide a long-term base of support in five key areas: research, patient education, physician education, international outreach, and access to care. The mission endowment's founding supporters are: Genentech, GlaxoSmithKline Oncology, Novartis Oncology, and sanofi-aventis US. There are several ways individuals, groups, corporations, and foundations can participate. One way is to establish a named endowed fund. Please contact the development office to talk about leaving a legacy through TACF.

TACF has hosted several events to educate patients and the public about important developments and progress in cancer medicine. Inaugural Public Forums were held in conjunction with the 2007 Breast Cancer Symposium and the 2008 Genitourinary Cancer Symposiums. Other critical expanded patient education offerings are being supported through the foundation including Cancer.Net, print materials, and advocate scholarships.

The new TACF brand and name were officially introduced April 1, 2008, as was the Foundation's new Web site: www. ascocancerfoundation.org Our name has changed slightly, but our charitable mission continues to be founded on four core tenets: research is at the heart of progress against cancer; cutting-edge knowledge is essential when to comes to treating people with cancer; getting good cancer care starts with getting good cancer information; and all patients with cancer deserve access to the best possible care.

Thank you ASCO members for your role in making ASCO the world's authoritative body on cancer. You provide the inspiration, knowledge, and hope for those who are teaching, researching, and providing patients with the highest stand of care worldwide. TACF raises funds that help make those achievements possible. Collaborating with TACF will ensure that today's achievements reach those who need them, as quickly as possible. Together we are making a world of difference in cancer care.

Kathleen Wiedemer is Director of Development for the ASCO Cancer Foundation.

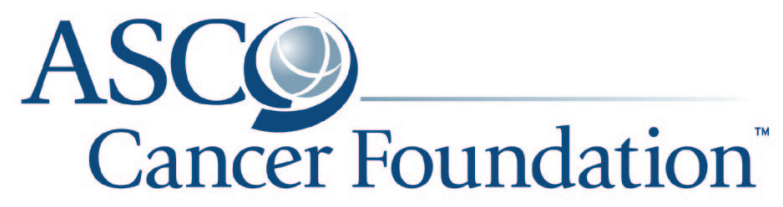

Making a world of difference in cancer care

DOI: 10.1200/JOP.0848001 